\title{
Evaluation of hydrokinetic energy potentials of selected rivers in Kwara State, Nigeria
}

\author{
Adeniyu Ganiyu Adeogun ${ }^{1 \dagger}$, Habeeb Oladimeji Ganiyu ${ }^{2}$, Laniyi Laniran Ladokun ${ }^{3}$, \\ Biliyamin Adeoye Ibitoye ${ }^{1}$ \\ ${ }^{1}$ Department of Civil Engineering, Kwara State University, Malete, 241104, Nigeria \\ ${ }^{2}$ Department of Civil Engineering, University of Ilorin, Ilorin, 240003, Nigeria \\ ${ }^{3}$ National Centre for Hydropower Research and Development, University of Ilorin, 240003, Ilorin, Nigeria
}

\begin{abstract}
This Hydrokinetic energy system is the process of extracting energy from rivers, canals and others sources to generate small scale electrical energy for decentralized usage. This study investigates the application of Soil and Water Assessment Tool (SWAT) in Geographical Information System (GIS) environment to evaluate the theoretical hydrokinetic energy potentials of selected Rivers (Asa, Awun and Oyun) all in Asa watershed, Kwara state, Nigeria. SWAT was interfaced with an open source GIS system to predict the flow and other hydrological parameters of the sub-basins. The model was calibrated and validated using observed stream flow data. Calibrated flow results were used in conjunction with other parameters to compute the theoretical hydrokinetic energy potentials of the Rivers. Results showed a good correlation between the observed flow and the simulated flow, indicated by ash Sutcliffe Efficiency (NSE) and $R^{2}$ of 0.76 and 0.85 , respectively for calibration period, and NSE and $R^{2}$ of 0.70 and 0.74 , respectively for the validation period. Also, it was observed that highest potential of $154.82 \mathrm{MW}$ was obtained along River Awun while the lowest potential of $41.63 \mathrm{MW}$ was obtained along River Asa. The energy potentials obtained could be harnessed and deployed to the communities around the watershed for their energy needs.
\end{abstract}

Keywords: Asa Watershed, Digital Elevation Model (DEM), Hydrokinetic Energy, Hydrological Response Unit (HRU), Nigeria

\section{Introduction}

Hydrokinetic is the process of extracting energy from ocean currents, waves, rivers, canals, tidal ocean and other water bodies to generate electric power. Hydrokinetic and wave energy technologies require no impoundments, so that the challenges and externalities associated with dam construction and reservoir creation are not relevant in its implementation [1]. The hydrokinetic energy conversion system has been described as the type of system that converts the kinetic energy of flowing water bodies with little or no head to generate other useable form of energy [2]. The available hydrokinetic power potentials that can be obtained from a river depend on the speed of the river, ocean, or tidal current and this is a function of the density of water and speed of the current cubed [3].

The breakthrough in this technology suggested that kinetic energy of flowing water can be used to generate electricity in flowing water without stress. Hydrokinetic energy is one of the newest clean energy that is derivable from the power of moving water and is unhindered by many of the weaknesses experienced with other clean energy sources [4]. Hence, globally, efforts have been channeled in this direction towards harnessing potential of rivers using hydrokinetic energy technology [5-7]. Natural Resources Canada [8] has completed a study to develop a methodology to assess the hydraulic kinetic energy contained in Canadian rivers. Also, in Nigeria, few studies have been initiated in this direction towards its development and implementation, for example, [9] conducted a field study at a selected site along Ero River, North-central Nigeria to assess the hydrokinetic energy conversion potentials of the river reach. Variants of data including hydrology, topography, bathymetry and digital elevation models (DEM) were used in conjunction with year round on-site measurements for the determination

Received January 11, 2018 Accepted April 11, 2019

${ }^{\dagger}$ Corresponding author

Email: adeniyi.adeogun@kwasu.edu.ng

Tel: +234-803-781-138

ORCID: 0000-0003-2109-0327

Copyright (c) 2020 Korean Society of Environmental Engineers 
of the hydraulic and hydrological parameters. These were used to obtain the instantaneous in-stream velocities necessary for the computation of the hydrokinetic power potential at selected location.

The application of soil and water assessment tool (SWAT) in hydrological analysis of upper catchment of Ikere Gorge Basin for hydrokinetic energy estimation was examined by [10]. The total theoretical hydrokinetic energy potential of the 10 basin selected was estimated as 36.4 MW. Also, potential hydrokinetic was estimated to have highest value in Oshe at Onikankan (9.542 MW) and lowest in Kojuoba at Olonje (0 MW).

The assessment of the Hydropower Potential of Kangimi Reservoir (KR) in Kaduna State Nigeria was conducted by [11]. The study evaluated the hydropower potentials of the KR and the result showed that KR can potentially generate 1.109 MW and $0.692 \mathrm{MW}$ if the KR dam axis is, respectively placed at 612 $\mathrm{m}$ and $604 \mathrm{~m}$ above mean sea level (AMSL).

Despite the fact that Nigeria is one of the most populous countries in Africa with a population of over 180 million [12], the informal sector of the economy that accommodates small scale industries that cater for majority of the people heavily depends on epileptic supply of power for economic production. In spite of the huge amount of capital invested in the generation and distribution of electrical energy in Nigeria on a yearly basis, quite a lot of people especially, the rural dwellers, most of which are the custodian of the cottage industries, are not privileged to be connected to the grid or have direct access to electricity. Additional problems such as vandalization of gas pipe line, seasonal wind variation, and obsolete machinery in the hydropower dams resulted in uneven distribution of power and sabotage of various sources of power generation in Nigeria [13].

Therefore, alternative energy generation to augment the generating capacities of existing hydropower plants and thermal stations to have stable power supply in Nigeria is inevitable. It is also a matter of urgency for energy stakeholders in Nigeria to harness the existing potentials of water resources in line with the changing world of hydrokinetic technology in the power generation as obtainable in many part of the world. A shift from other sources of energy to recent technology of hydrokinetic power production will add more values to economic growth and development of both the private and public sectors. According to Federal Ministry of Water Resources [14], small hydropower schemes have been integrated into some dam projects across the country to increase energy supply of the nation. However, the hydrokinetic potentials of river currents in Nigeria have been, to date, largely unexplored [15].

Consequently, this research examined the potentialities of using an hydrological model, SWAT embedded in GIS environment to model the hydrology of Asa watershed in Kwara State, Nigeria and used the modeling results in conjunction with other parameters to estimate the theoretical hydrokinetic energy potential of selected Rivers in the catchment.

\section{Materials and Methods}

\subsection{Study Area}

The study area is located between Latitude $8^{0} 36^{\prime}$ and $8^{0} 24^{\prime}$ North and Longitudes $4^{0} 36^{\prime}$ and $4^{0} 10^{\prime}$ East with estimated total area of about 639,239.07 Ha and it lies within Kwara State in Nigeria. The topography of the area could be described as a fair representative of surrounding plains with undulating and very broad and gentle slopes. The study area is characterized with an altitude between $265 \mathrm{~m}$ and $457 \mathrm{~m}$ AMSL.

The climate of the watershed could be described as humid tropic type and characterized by both wet and dry seasons with a mean annual temperature that ranges from $25-28.9^{\circ} \mathrm{C}$ during the wet season and $33-37^{\circ} \mathrm{C}$ in the dry season [16]. The watershed has an annual mean rainfall of about $1,150 \mathrm{~mm}$. Some of the major rivers within the catchment include River Asa, River Oyun, and River Awun. Fig. 1 shows the location Map of the study area.

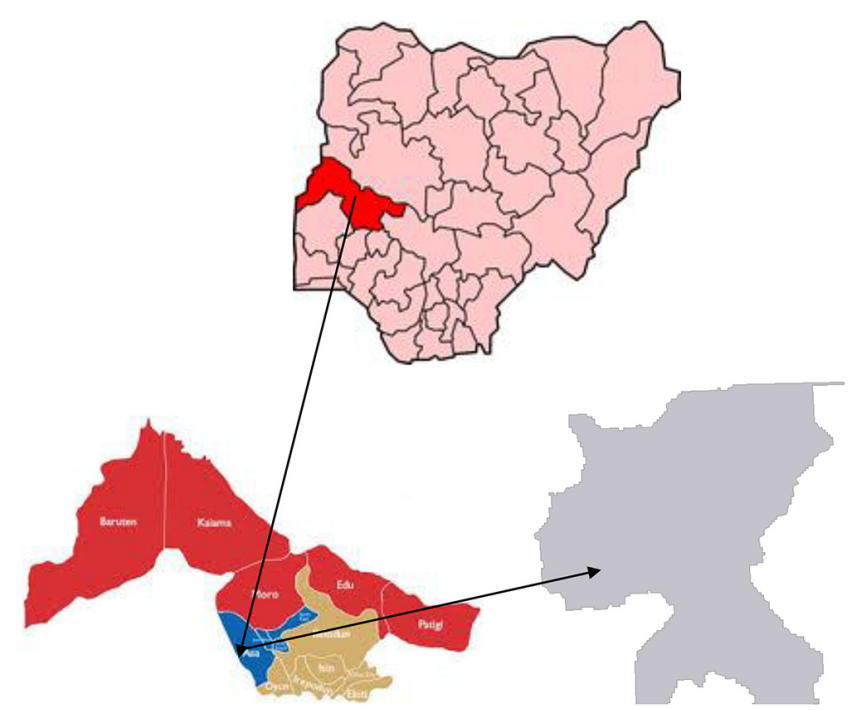

Fig. 1. Map of Nigeria showing the location of the watershed.

\subsection{SWAT Model Selection and Description}

In this study, SWAT was selected as the modeling tool. The tool was developed by the United States Department of Agriculture to predict the impact of land management practices on water, sediment and agricultural chemical yields in large un-gauged basins [17]. The modeling tool was interfaced with Mapwindow GIS to simulate the hydrology and predict the flow into sub-basins in the watershed. The SWAT model is a long-term, continuous simulation watershed model which operates on a daily time step and is designed to predict the impact of management on water and sediment. The model is physically based, computationally efficient, and capable of simulating a high level of spatial details by allowing the division of watersheds into smaller sub watersheds.

SWAT incorporates the effects of weather, surface runoff, evapo-transpiration, irrigation, sediment transport, groundwater flow, crop growth, nutrient yielding, pesticide yielding and water routing, as well as the long term effects of varying agricultural management practices $[18,19]$. In the SWAT model, the watershed is partitioned into sub basins that are further subdivided into one or several homogeneous hydrological response units (HRUs) with relatively unique combinations of land cover, soil and topographic 
conditions. The hydrological component of the model calculates soil-water balance at each time step based on daily amounts of precipitation, runoff, evapo-transpiration, percolation and base flow.

\subsection{Model Input Data Collection and Processing}

The spatially distributed data (GIS input) needed for the running of Mapwindow SWAT include the DEM, soil data, land use and stream network layers. Weather data are also necessary for prediction of stream flow in the watershed. The GIS interface of the model was used to discretize the catchment area and geoprocessed the spatial data into formats required by the model.

\subsubsection{DEM}

Topography of a place is defined by a DEM that describes the elevation of any point in a given area at a specific spatial resolution. $90 \mathrm{~m}$ by $90 \mathrm{~m}$ resolution DEM of the study area was obtained from Shuttle Radar Topography Mission SRTM website [20]. The DEM was processed and used to delineate the watershed and analyse the drainage patterns of the land surface terrain. Sub basin

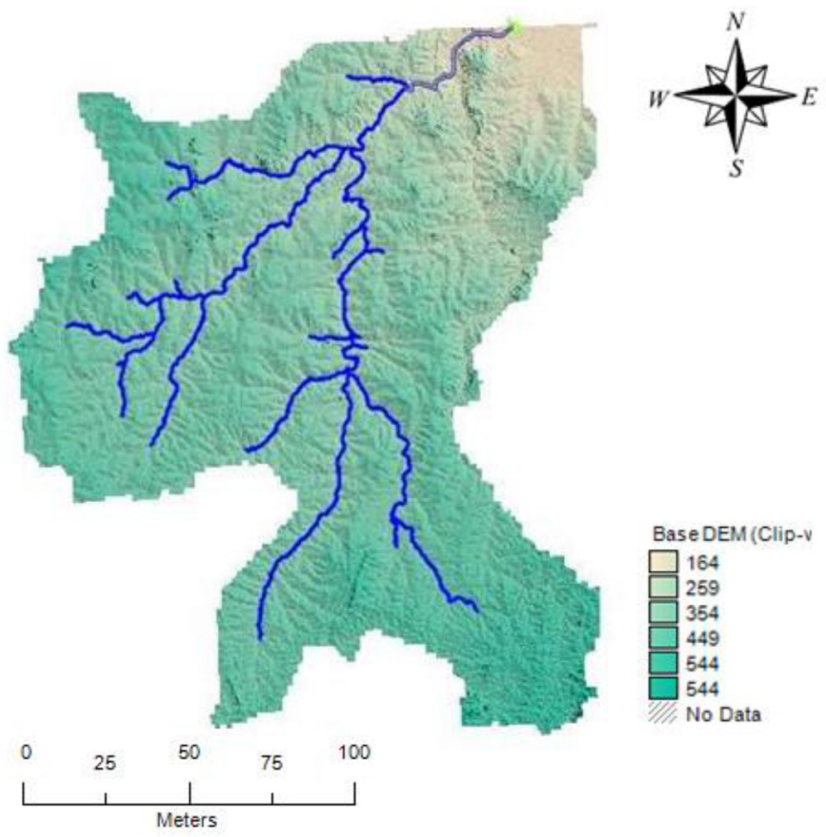

Fig. 2. Digital elevation model of the study area attributed with stream network. parameters such as slope gradient, slope length of the terrain, and the stream network characteristics such as channel slope, length, and width were derived from the DEM. Fig. 2 shows the DEM of the study area.

\subsubsection{Landuse and land cover}

Land use is one of the most important factors that affect surface erosion, runoff, and evapo- transpiration in a watershed. Land use map of the study area was extracted from the Global Land Cover Characterization (GLCC) database and used to estimate vegetation and other parameters representing the watershed area. The GLCC database was developed by United States Geological Survey and has a spatial resolution of $1 \mathrm{~km}$ and 24 classes of land use representation [21].

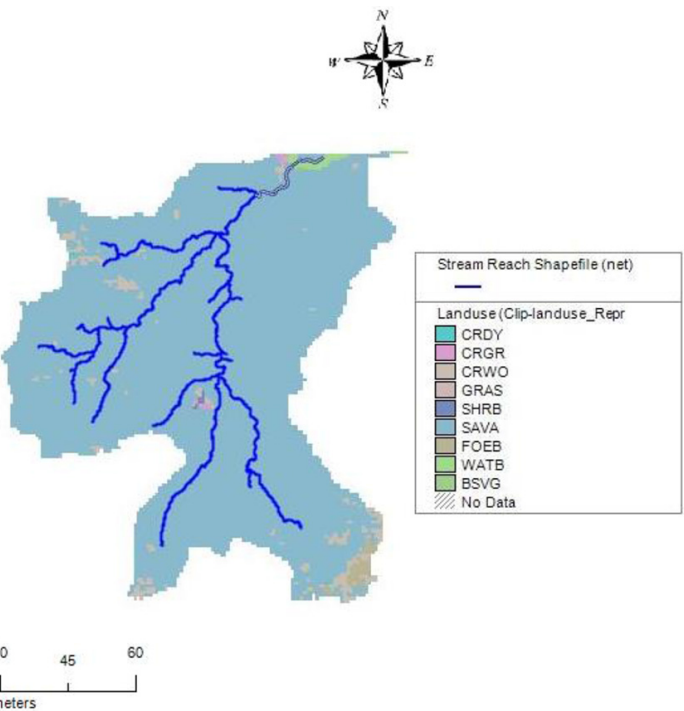

Fig. 3. Landuse map of the study area.

Fig. 3 shows the land use and land cover of the study area while Table 1 provides information on land use of the study area. From Table 1, it could be inferred that the watershed is dominated by savannah type of vegetation having coverage of about $94 \%$ of the watershed.

\subsubsection{Digital soil data}

SWAT requires different soil textural and physicochemical properties such as soil texture, available water content, hydraulic con-

Table 1. Information on Land use of the Study Area

\begin{tabular}{cclcc}
\hline S/N & SWAT Code & \multicolumn{1}{c}{ Description } & Area(Ha) & \multicolumn{1}{c}{ \% of Watershed } \\
\hline 1 & SAVA & Savannah & $603,710.23$ & 94.44 \\
2 & CRWO & Cropland/woodland mosaic & $10,288.11$ & 1.61 \\
3 & CRDY & Dryland cropland and pasture & 56.39 & 0.01 \\
4 & SHRB & Shrubland & 749.11 & 0.12 \\
5 & CRGR & Cropland/grassland mosaic & 749.11 & 0.12 \\
6 & WATB & Waterbodies & $3,182.47$ & 0.50 \\
7 & BSVG & Barren or sparsely vegetated & 589.19 & 0.09 \\
\hline
\end{tabular}


Table 2. Information on Soil Texture of the Study Area

\begin{tabular}{ccccc}
\hline S/N & SWAT Code & Description & Area(Ha) & \% of Watershed \\
\hline 1 & I-Ql-Re-1281 & Loam & $32,824.66$ & 5.13 \\
2 & Lf1-1421 & Sandy loam & $5,526.61$ & 0.86 \\
3 & Lf12-a-1430 & Clayey loam & $159,378.61$ & 24.93 \\
4 & Lf26-a-1443 & Sandy clayey loam & $415,467.82$ & 64.99 \\
5 & Lf49-1475 & Sandy clayey loam & $6,126.74$ & 0.96 \\
6 & Nd3-1565 & Sandy loam & $19,914.63$ & 3.13 \\
& Total & & $639,239.07$ & 100.00 \\
\hline
\end{tabular}

ductivity, bulk density and organic carbon content for different layers of each soil type. Digital soil data for the study was obtained from Harmonised Digital Soil Map of the world (HWSD v1.1) produced by Food and Agriculture Organization of the United Nations [22]. Table 2 provides detailed information on soil of the study area which shows that the area is dominated by clayey loam soil.

\subsubsection{Weather and flow data}

SWAT requires daily meteorological data that can either be read from a measured data set or generated by a weather generator model. The weather data used in this study include daily precipitation, minimum and maximum temperature, relative humidity, wind, and solar radiation. These data were obtained from Nigerian Meteorological Agency (NIMET) Ilorin zone and covers a period of 10 y, i.e., 1 August 2004 to 31 July 2014. Observed flow data used for the calibration and validation of the model covers a period of 6 hydrological years i.e., August, 2008 to July, 2014.

\subsection{Watershed Delineation and Creation of HRU}

Watershed delineation tool on the Mapwindow GIS allows the user to sub-divide a watershed into several smaller hydrologically connected units which can be used for watershed characterization and modelling. The study area was divided into sub-basins using the GIS component of the SWAT model. The watershed was de

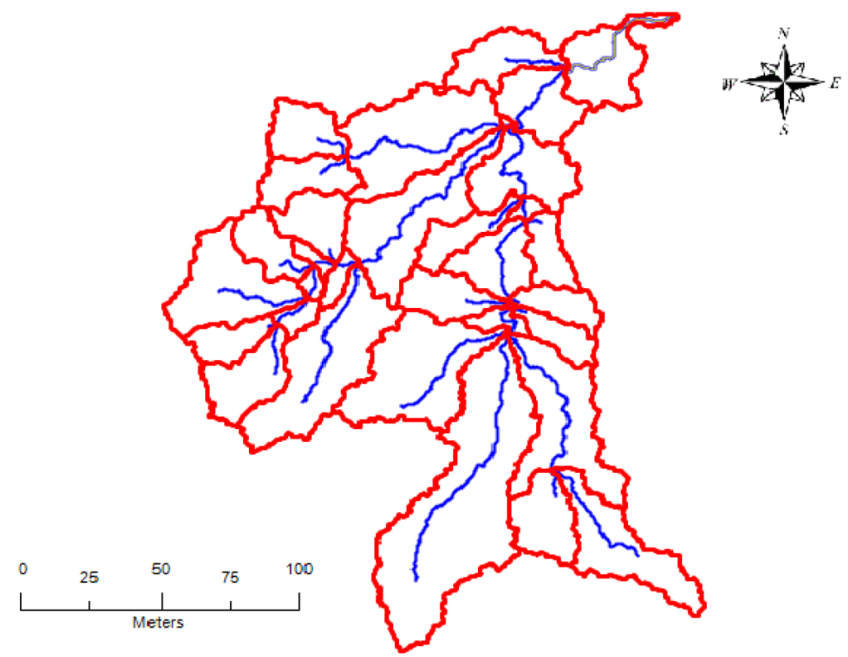

Fig. 4. Delineation of watershed into 31 sub-basins and 42 hydrological response units (HRUs). lineated into 31 sub-basins which are then further subdivided into 42 HRUs that consist of homogeneous land use is to increase the accuracy of the prediction of model results from the sub basin level. Fig. 4 shows the stream network and the delineation of the watershed into sub-basins.

\subsection{SWAT Setup and Configuration}

The SWAT interface provides an option to choose the method to be adopted for the estimation of surface runoff (Curve Number or Green and Ampt method) and channel water routing (variable or Muskingum method). Also, for the estimation of potential evapo-transpiration (PET), methods such as Priestley, PenmanMonteith or Hargreaves are available. In this study, SWAT was run for a period of 10 hydrological years at a daily time step adopting Curve number method for estimating surface runoff from precipitation, variable storage method for channel water routing and Hargreaves method for estimating the PET from the watershed. The Hargreaves method was used for the estimation of PET because of its simplified equation which requires only two climatic parameters, that is, the temperature and incident radiation.

\subsection{Performance Evaluation, Model Calibration and Validation}

Performance of the SWAT model was assessed by comparing the models ability to match monthly values of observed flow (mean monthly discharge). In addition to comparing mean values for the calibration and validation periods, model performance was evaluated using statistical parameters such as the NSE and Coefficients of Determination $\left(\mathrm{R}^{2}\right)$ as represented in Eq. (1) and (2), respectively.

$$
\begin{gathered}
R^{2}=\frac{\left[\sum_{i}\left(Q_{m, i}-\overline{Q_{m}}\right)\left(Q_{s, j}-\overline{Q_{s}}\right)\right]^{2}}{\sum_{m, j}\left(Q_{m, j}-\overline{Q_{m}}\right)^{2} \sum_{i}\left(Q_{s, i}-\overline{Q_{s}}\right)^{2}} \\
N S E=1-\frac{\sum_{i}\left(Q_{m, i}-Q_{s, i}\right)^{2}}{\sum_{i}\left(Q_{m, i}-\overline{Q_{m}}\right)^{2}}
\end{gathered}
$$

In Eq. (1) and (2), $Q_{m}$ is the measured discharge, $Q_{s}$ is the simulated discharge, $\overline{Q_{m}}$ is the average measured discharge and $\overline{Q_{s}}$ is the average simulated discharge. NSE values can range from 0 to 1 . Perfect agreement between predicted and observed data results in NSE $=1$; an NSE value of 0 indicates that the mean 
of the observed data is as accurate as the model predictions. For watershed scale modelling, NSE values of 0.36 to 0.75 are generally considered fair, while values greater than 0.75 indicate good model performance [23].

\subsection{Computation of Theoretical Hydrokinetic Energy Potentials}

Calibrated flow results of the model were used to estimate the theoretically available in- stream hydrokinetic energy potential of selected Rivers within the watershed. This was achieved using Eq. (3) in line with previous resource assessment of hydrokinetic energy potential [8].

$$
P_{t h}=\gamma \times Q \times \Delta H
$$

In Eq. (3), $\mathrm{P}_{\text {th }}$ is the theoretical hydrokinetic energy in Watts, $\mathrm{Q}$ is the segment specific average water discharge $\left(\mathrm{m}^{3} / \mathrm{s}\right), \Delta H$ is the Hydraulic head (m) obtained from geo-processing of the DEM using the GIS component of the model and $\gamma$ is the specific weight of water. The computations were finalised by exporting the data into Microsoft Excel spreadsheet software package to estimate the theoretical hydrokinetic energy potential along each of the River channels.

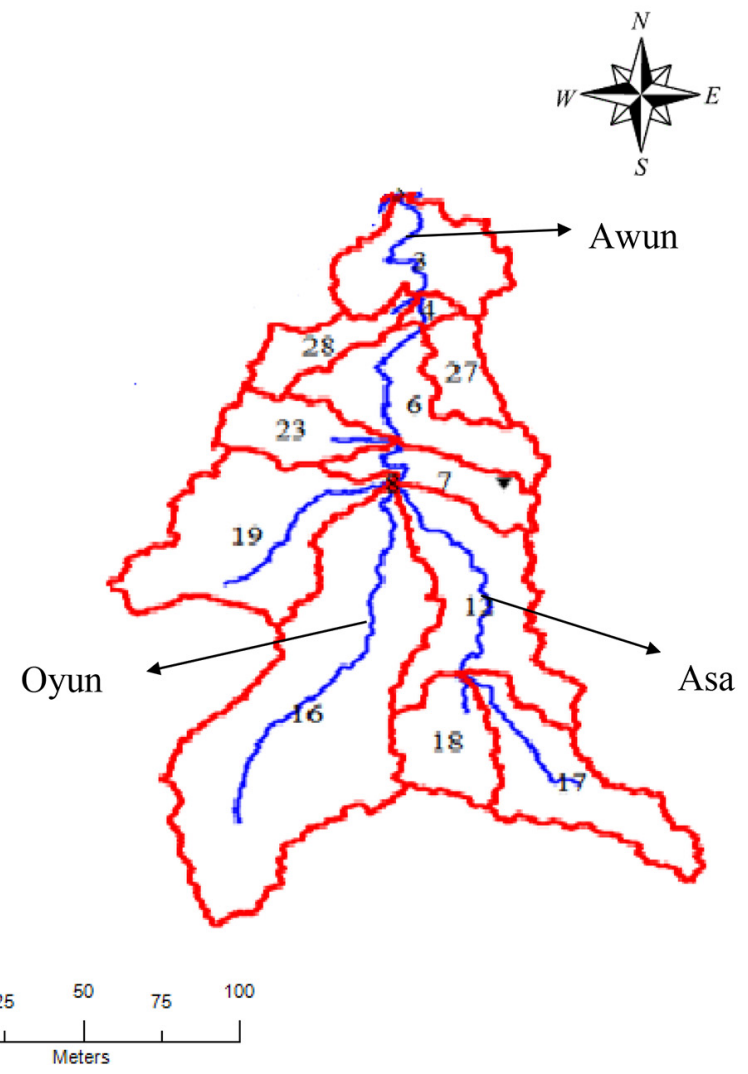

Fig. 5. Selected Rivers for the computation of hydrokinetic energy potential.

Fig. 5 shows the selected Rivers for the computation of hydrokinetic energy potential. Flow chart of the methodology adopted for the study is presented in Fig. 6 .

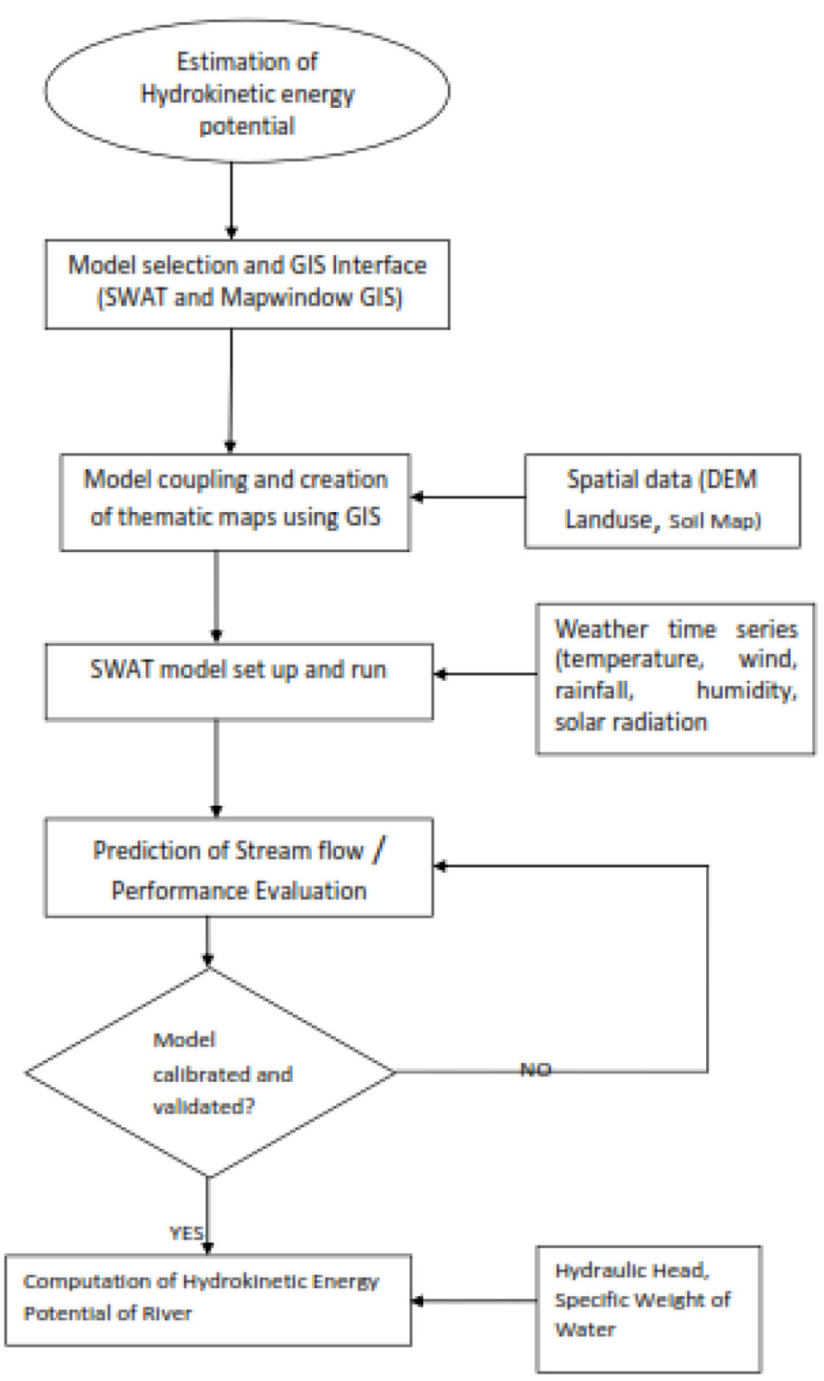

Fig. 6. Flow chart of the stages involved in the estimation of hydrokinetic energy of the selected rivers.

\section{Results and Discussion}

\subsection{Performance Evaluation, Model Calibration and Validation}

Performance evaluation of the model was achieved by comparing the observed and simulated monthly inflow at Asa River for both the calibration and validation periods. In total, 14 parameters were selected to be calibrated through the Parasol optimization method. The model was calibrated with the observed monthly inflow from 2008 to 2010, and cross-validated with another set of independent data set from 2011-2014. Plot of observed data against calibrated results are presented in Fig. S1 and S2. Results showed a good correlation between the observed flow and the simulated flow, indicated by NSE and $\mathrm{R}^{2}$ of 0.76 and 0.85 , respectively for calibration period, and NSE and $\mathrm{R}^{2}$ of 0.70 and 0.74 , respectively for the validation period. Furthermore, most of the data for the calibration 
and validation period fall within the confidence interval of $95 \%$. The plots of the standardised residuals for both the calibration and validation periods are as shown in Fig. S3 and S4, respectively.

\subsection{Prediction of Average Daily and Annual Mean Discharge into Sub-basins}

The results of average daily discharge into sub-basins of the watershed are as shown in Fig. S5. River reach in sub-basin 3 has the highest value of $2.79 \mathrm{~m}^{3} / \mathrm{s}$ while the reach in sub-basin 16 has the lowest value of $0.49 \mathrm{~m}^{3} / \mathrm{s}$. Model results showed that sub-basin 3 has the highest value of $336.6 \mathrm{~m}^{3} / \mathrm{s}$ for maximum discharge in the watershed while sub-basin 16 has the lowest value of 38.91 $\mathrm{m}^{3} / \mathrm{s}$ for maximum discharge on the watershed. The results also showed that sub-basin 3 has the highest value of $1,053.4 \mathrm{~m}^{3} / \mathrm{s}$ for Annual Mean Discharge from the watershed. However, the lowest value of $16.02 \mathrm{~m}^{3} / \mathrm{s}$ was recorded in sub-basin 29 .

\subsection{Estimation of Hydrokinetic Energy Potential}

In this study, theoretical hydrokinetic potential of Asa River, having a stream length of $76,713 \mathrm{~m}$ and an annual average flow of 59 $\mathrm{m}^{3} / \mathrm{s}$ was estimated as $41.63 \mathrm{MW}$. Oyun River has a length of $64,381 \mathrm{~m}$ and an average annual stream flow of $125.5 \mathrm{~m}^{3} / \mathrm{s}$ was estimated as 98, $39 \mathrm{MW}$ while River Awun, with an average annual flow of $1,053.4 \mathrm{~m}^{3} / \mathrm{s}$ and length of 31,736 $\mathrm{m}$ has the highest estimated hydrokinetic potential of about 154.82 MW. Details of theoretical hydrokinetic potentials of the Rivers can be found in Table S1. However, it is important to state that these values may be affected by factors such as turbine design, type, efficiency and mode of deployment and River use in the course of harnessing the potential on site.

The estimated hydrokinetic potentials most especially for Asa River in this work are comparable with the results obtained by [10] where the total theoretical hydrokinetic energy potential of selected basin upper catchment of Ikere Gorge Basin in Oyo State, Nigeria was analyzed for hydrokinetic energy and an estimated potential of 36.4 MW was obtained. Larger theoretical hydrokinetic potential estimated for River Awun (154.82 MW) may be due to the increased flow velocity of water at the location which emptied directly into River Niger, the largest River those transverses the country from Northern region to Southern region.

\section{Conclusions and Future Outlook}

Based on the outcome of this study, the following points can be concluded:

i . Naturally occurring hydrokinetic energy potentials exist along the three selected Rivers in the study area, namely, Asa, Oyun and Awun Rivers in Kwara State of Nigeria.

ii. SWAT embedded in GIS environment can be employed in the assessment of hydrokinetic energy of rivers in other area of Nigeria and sub Saharan Africa.

iii. Performance evaluation using coefficient of determination $\left(\mathrm{R}^{2}\right)$ and NSE showed that the model performance is satisfactory in predicting the streamflow.

iv. The estimate of the total annual theoretical hydrokinetic resource for Asa River was 42.63 MW, Oyun River was estimated as 98.39 MW while Awun River potential was obtained as $154.82 \mathrm{MW}$.

Therefore, with deployment of appropriate technology and commitment from the government and other stakeholders, estimated energy potentials along the selected Rivers could be harnessed in the nearest future and serve as alternate source of energy for the rural dwellers most especially settlements within the watershed that are not connected to national grid.

\section{Acknowledgment}

Researchers acknowledge the support of the staff and students of the department of Civil Engineering, Kwara State University, Malete, Nigeria for their support towards the successful completion of this work.

\section{References}

1. Bahleda M, Hosko MA. Assessment of water power potential and development needs. In: Electric Power Research Institute California Final Report; 2007.

2. Ladokun L, Ajao KR, Sule BF, Adeogun N. Hydrokinetic energy resource estimates of River ERO at Lafiagi, Kwara State, North-Central Nigeria. Nigerian J. Technol. Res. 2016;11:58-63.

3. Johnson JB, Pride DJ. River, tidal, and ocean current hydrokinetic energy technologies: Status and future opportunities in Alaska. In: Alaska energy authority by the Alaska Center for Energy and Power. 1 November 2010; Alaska.

4. Evan M. Hydrokinetic power: An analysis of its performance and potential in the Roza and Kittas canals [dissertation]. Olympia: Evergreen State College; 2012.

5. Mourad B, Enguerran G, Guillou S, Goossens X. Modelling river hydrokinetic energy in large rivers: Maroni river in French Guiana. 2016, cited 20 December 2017. Available from: https://hal.archives-ouvertes.fr/hal-01514240.

6. Kalnacs A, Kalnacs J, Mutule A, Persis U. Methods for estimation of the river flow potential for hydrokinetic power generation. Latv. J. Phys. Tech. Sci. 2014;2:1-10.

7. Lalander E. Modelling hydrokinetic energy resource for in-stream energy converters [dissertation]. Uppsala: Uppsala Univ.; 2010;1-57.

8. Canmet Energy. Assessment of Canada's hydrokinetic power potential. In: Phase I Report methodology and data review; March 2010; Ottawa.

9. Ladokun LL, Ajao KR, Adeogun AG. Hydrokinetic energy resource estimates of River ERO at Lafiagi, Kwara State, North-Central Nigeria. Nigerian J. Technol. Res. 11:58-63.

10. Wahab S. Ifabiyi IP, Adeogun AG. SWAT analysis of Ikere Gorge basin for hydrokinetic power estimation in selected rural settlements of Oke Ogun, Nigeria. Ruhuna J. Sci. 2017;8:24-43.

11. Otuna JA. Onemano JI, Alayand AW. Assessment of the hydropower potential of Kangimi reservoir in Kaduna state Nigeria. Nigerian J. Technol. 2012;31:300-307.

12. Vanguard Newspaper. NPC puts Nigeria's population at $198 \mathrm{~m}$ 
[Internet]. C2018 [cited 12 December 2018]. Available from: https://www.vanguardngr.com/2018/04/npc-puts-nigerias-population-198m/.

13. Emovon I, Samuel OD, Mgbemena CO, Adeyeri MK. Electric power generation crisis in Nigeria: A review of causes and solutions Int. J. Integr. Eng. 2018;10:47-56.

14. Federal Ministry of Water Resource. Dams and reservoir operations [Internet]. [cited 2 December 2017]. Available from: http://waterresources.gov.ng/dams-and-reservoir-operations/.

15. Ladokun LL, Ajao KR, Sule BF. Hydrokinetic energy conversion systems: Prospects and challenges in Nigerian hydrological setting. Nigerian J. Technol. 2013;32:371-378.

16. Jimoh HI, Ishola AL. Problems of suspended sediment loads in Asa River catchment, Ilorin, Nigeria. Pakistan J. Soc. Sci. 2009;6:19-25.

17. Arnold JG, Williams JR, Maidment DR. Continuous-time water and sediment-routing model for large basins. J. Hydraul. Eng. 1995;121:171-183.

18. Neitsch SL, Arnold JG, Kniry JR, Scrinivasan R. Williams JR.
Soil and water assessment tool-user's manual-version 2000. Temple (TX): Blackland Research Centre; 2002.

19. Neitsch SL, Arnold JG, Kiniry JR, Williams JR. Soil and water assessment tool-theoretical documentation-version 2005. Temple (TX): Blackland Research Centre; 2005.

20. CGIAR. SRTM 90m digital elevation data [Internet]. [cited 20 July 2017]. Available from: http://srtm.csi.cgiar.org/.

21. USGS. Global land cover characterization [Internet]. [cited 25 November 2017]. Available from: https://www.usgs.gov/centers/eros/science/usgs-eros-archive-land-cover-products-global-land-cover-characterization-glcc?qt-science_center_objects= $0 \#$ qt-science_center_objects.

22. Nachtergaele F, Velthuizen HV, Verelst L. Harmonized world soil database. In: Fod and Agriculture Organization of the United Nations; March 2009; Rome, Italy. 2008. Laxenburg: IIASA; 2008.

23. Motovilov YG, Gottschalk L, England K, Rodhe A. Validation of distributed hydrological model against spatial observations. Agric. Forest Meteorol. 1999;98-99:257-277. 